\title{
Enhancing global monsoon research in ocean drilling
}

\author{
Pinxian Wang \\ IODP-PAGES Workshop, Shanghai, China, 7-9 September 2017
}

Between 2013 and 2016, seven deep-ocean drilling expeditions were completed by the International Ocean Discovery Program (IODP) to explore the Cenozoic history of the Indian, East Asian and Australian monsoons. If the former Ocean Drilling Program (ODP; 1983-2003) cruises are included, the drilling activities covered the African and American monsoons regions as well (Fig.1). To further promote paleo-monsoon researches, 48 scientists from 12 countries attended the IODP-PAGES workshop on "Global Monsoon in Long-term Records". Co-chief scientists of the IODP/ODP monsoon-related expeditions presented their scientific findings, discussed the research directions and made recommen dations for the future IODP science program.

The workshop started with presentations given by members of the former PAGES Global Monsoon working group. Traditionally, the variability of the monsoon has been studied almost exclusively on regional scales. With the application of remote sensing and other new techniques since the last decade, the concept of the Global Monsoon has been introduced as a global-scale seasonal reversal of the monsoon circulation associated with the Inter-Tropical Convergence Zone (ITCZ) migration. PAGES established the "Global Monsoon and Low-Latitude Processes: Evolution and Variability" working group in 2007. The working group conducted two successive symposia in 2008 (Wang et al. 2009) and 2010 (Wang et al. 2011), published a special issue in Climate Dynamics (Wang et al. 2012) and two synthesis papers (Wang et al. 2014, 2017).

A number of questions were discussed during the workshop, such as the applicability of the Global Monsoon concept at geological time scales, monsoon response to external forcing and internal feedback, initiation of the current monsoon systems, the use and misuse of monsoon proxies, and the role of monsoon in global climate system. After extensive discussions, workshop participants recommended that global monsoon and its role in the hydrological cycle should be incorporated in the IODP Science Plan beyond 2023.

Although monsoon precipitation accounts only for one third of the modern global total rainfall, its spatial-temporal variation is the most mutable component in the global hydrological cycle. Together with ENSO and trade winds, global monsoon comprises a major low-latitude component of the world climate system, and thus may provide a key to understanding the controlling factors of the hydrological cycle.

The workshop stressed the value of deep-time monsoon in high resolution records. Despite prominent progress in generating high-quality records over the past decade, the majority of high-resolution paleo-monsoon records remains restricted to the late Quaternary, with only a limited number of sediment sequences at several IODP sites tracing back beyond the Pliocene. A much longer time coverage is urgently needed to reveal the monsoon changes at the Hot- to Ice-House transition, and the tectonic background of when and how the modern monsoon systems established.

Another topic of discussion was monsoon proxies. Chemical and isotopic proxies have been extensively and successfully used in paleo-monsoon reconstructions, but opinions on their interpretation are divergent. Scientific debates call for further calibration of the current proxies and for development of new proxies, especially those indicative of the global monsoon. As many scientists working in monsoon regions tend to interpret all variance in the context of monsoon circulation, it is essential to discriminate the component of climate changes related from those unrelated to monsoon variations.

Workshop attendees also called for an extension of the geographic coverage of ocean drilling. The existing deep-sea monsoon records are heavily biased towards the Northern Hemisphere. High-resolution pre-Quaternary records from the Southern Hemisphere, including monsoon areas off South America, Australia and South Africa, are urgently needed. It is also expected that future targets of paleo-monsoon studies will continue to have a strong focus on margin environments, requiring improvements of international political relationships required to gain access to these regions.

\section{AFFILIATION}

State Key Laboratory of Marine Geology, Tongji University, China

\section{CONTACT}

Pinxian Wang: pxwang@tongji.edu.cn

\section{REFERENCES}

Wang P et al. (2009) PAGES news 17: 82-83

Wang P et al. (2011) PAGES news 19: 86-87

Wang P et al. (2012) Clim Dyn 39(5)

Wang P et al. (2014) Clim Past 10: 2007-2052

Wang P et al. (2017) Earth Sys Rev 174: 84-121

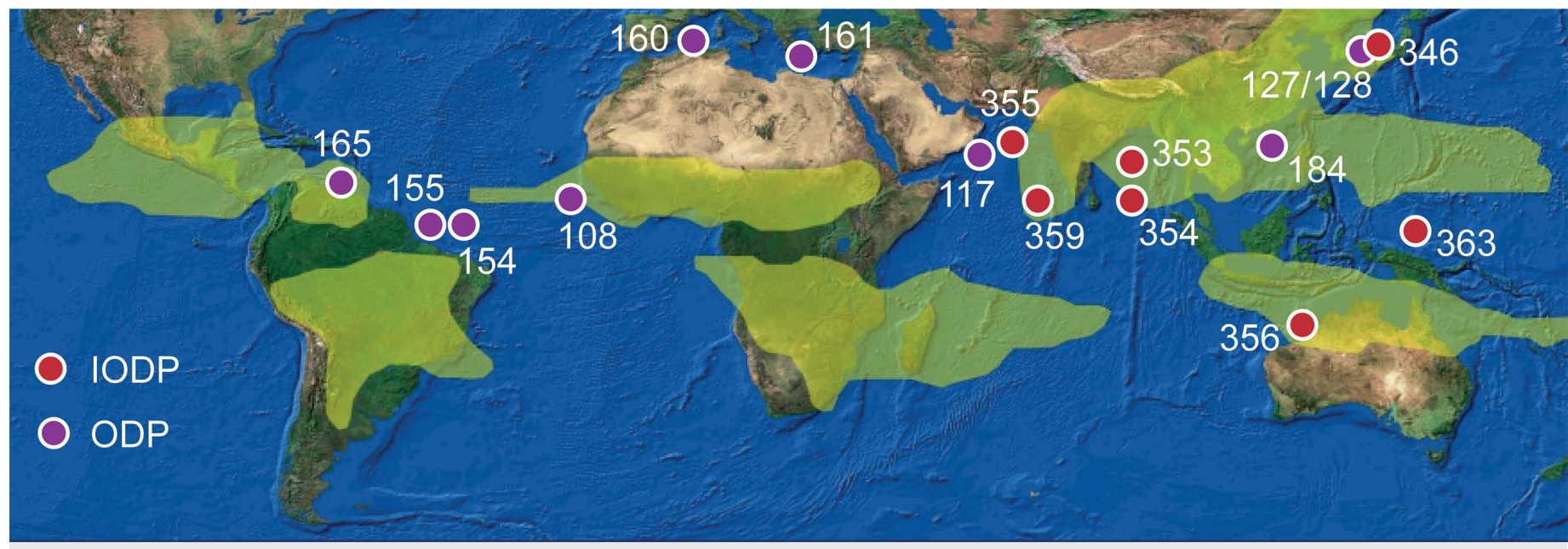

Figure 1: Map showing all IODP/ODP monsoon-expedition coring sites. 